TITLE: Kinetic models comparison for steam gasification of different nature fuel chars

AUTHORS: J. Fermoso, B. Arias, C. Pevida, M.G. Plaza, F. Rubiera*, J.J. Pis

ADDRESS: Instituto Nacional del Carbón, CSIC. Apartado 73. 33080 Oviedo, Spain

*Corresponding author: Dr. Fernando Rubiera

Instituto Nacional del Carbón, C.S.I.C.

Apartado 73

33080 Oviedo (Spain)

Telephone: +34985118975

Fax: +34985297662

E-mail: frubiera@incar.csic.es 


\title{
Kinetic models comparison for steam gasification of different nature fuel chars
}

\author{
J. Fermoso, B. Arias, C. Pevida, M.G. Plaza, F. Rubiera, J.J. Pis \\ Instituto Nacional del Carbón, CSIC. Apartado 73. 33080 Oviedo, Spain.
}

\begin{abstract}
The reactivity in steam of five different types of solid fuels (two coals, two types of biomass and a petcoke) has been studied. The fuel chars were obtained by pyrolysis in a fixed-bed reactor at a temperature of $1373 \mathrm{~K}$ for $30 \mathrm{~min}$. The gasification tests were carried out by thermogravimetric analysis (TGA) at different temperatures and steam concentrations. The reactivity study was conducted in the kinetically controlled regime and three representative gas-solid models, volumetric model (VM), grain model (GM) and random pore model (RPM), were applied in order to describe the reactive behaviour of the chars during steam gasification. The kinetic parameters of these models were derived and the ability of the models to predict conversion and char reactivity during gasification was assessed. The best model for describing the behaviour of the samples was the RPM. The effect of the partial pressure of steam in gasification was studied, and the reaction order with respect to steam was determined. The reactivity of the chars was compared by means of a reactivity index. Biomass exhibited a higher reactivity than coals and petcoke. However, significant differences in reactivity were observed between the two types of biomass used, which could be due to catalytic effects.
\end{abstract}

Keywords: coal, biomass, petcoke, char gasification, kinetic models

\section{Introduction}

Hydrogen is considered as the major energy carrier of the future, so an increase in the hydrogen demand can be expected. In view of this, more hydrogen must be generated from different sources to ensure the stability of supplies. Nowadays, about half of worldwide hydrogen production comes from natural gas reforming, and 98\% of the total production comes from fossil fuels (1). The use of natural gas as a feedstock has the drawback of the volatility of natural gas prices and the limited reserves. For these reasons, alternative sources are being considered in order to reduce the dependence of the energy system on fossil fuels. This situation is generating increasing interest in lower cost fuels, that can be used to produce 
mixtures of hydrogen and carbon monoxide by means of gasification. This process which converts carbon-based feedstocks to a fuel gas that can be used for energy or chemical production is already a well-established technology. Co-gasification of coal with other less carbon containing fuels, such as biomass, presents the advantage of a reduction in $\mathrm{CO}_{2}$ emissions, and even a net reduction, if $\mathrm{CO}_{2}$ capture is considered as part of the process (2). Renewable energies are indigenous sources; consequently, an increase of their use will have positive implications for ensuring supplies. Additionally, renewable energies have a lower environmental impact than fossil fuels, so their implementation will also help to preserve the equilibrium of ecosystems (3). In addition, the higher thermochemical reactivity of biomass will facilitate the conversion and upgrading of the fuel.

Co-gasification technologies have recently been successfully demonstrated on a large scale (4). However the actual operational experience is limited and more confidence in the technology is needed. Additionally, flexible gasification designs are needed so that these diverse fuels can be used efficiently. What is more, being able to predict the behaviour of different types of fuels in an existing gasification reactor is of great importance when variable feedstocks are used.

Gasification can be divided in two main stages: pyrolysis and subsequent gasification of the remaining char, the second stage being the controlling step of the overall process. For these reasons, knowledge about the reactivity of chars, and their variation as reaction progresses, is fundamental for the design of gasification reactors, as char gasification determines the final conversion achieved in the process (5). Regarding the kinetics of gasification, the reactivity of the material depends on the gasifying agent used and the operation conditions, such as pressure and temperature $(6,7)$. Gasification is usually carried out with air, oxygen or steam mixtures. The advantage of using steam is that this process yields higher amounts of hydrogen. On other hand, several factors related to the characteristics of char affect the rate of reaction under gasification in a steam atmosphere. Of these, the nature and the thermal history of the char, its pore structure, and fuel chemical composition are considered to be responsible for the biggest differences in results $(8,9,10)$. Additionally, inherent mineral matter in these fuels can play and important role in gasification due to catalytic reactions $(11,12)$.

In order to predict the behaviour of coal during gasification, several models have been proposed with different degrees of complexity $(13,14)$. However, high complexity mathematical models are difficult to apply, and are not frequently used for practical purposes. For this reason, simpler models are preferred for approximate computations in design calculations (7). 
The aim of the present work was to study the steam gasification reactivity and kinetics of five different types of fuels (two coals, a petroleum coke and two samples of biomass). For this purpose, three different mathematical models were applied, and their validity in predicting the conversion and reactivity of the samples during gasification in steam was assessed. Kinetic parameters were derived in order to determine the kinetic model which best represents the behaviour of the chars during the gasification process.

\section{Experimental}

\subsection{Fuel samples}

The raw materials used in this work comprised two bituminous coals with different ash contents (WI, PT), a petcoke (PC) and two types of biomass: residues of chestnut (CH) and olive stones (OS). Coal PT and petcoke were supplied by a power generation company. These fuels are used in a gasification plant. Coal WI is a low volatile bituminous coal from the USA. Biomasses used in this work, $\mathrm{CH}$ and $\mathrm{OS}$, are residues produced in the wood industry and in the olive oil production, respectively.

These materials were ground, sieved and the resulting 1-2 $\mathrm{mm}$ size fraction was used for the pyrolysis tests. The residues of chestnut were used in the form pellets with a diameter of 4 $\mathrm{mm}$ and a height of $1 \mathrm{~mm}$. The proximate and ultimate analyses of the samples are given in Table 1.

\subsection{Char preparation}

The chars were prepared by devolatilisation of the raw fuels in a quartz fixed bed reactor (20 mm internal diameter) heated by an electric furnace (Carbolite Furnaces, CTF 12/65/550) under a nitrogen stream $\left(150 \mathrm{~cm}^{3} / \mathrm{min}\right)$. A thermocouple in contact with the sample bed was used to control the pyrolysis temperature. Samples were subjected to a heating rate of 15 $\mathrm{K} / \mathrm{min}$ up to $1373 \mathrm{~K}$ and held at this temperature for $30 \mathrm{~min}$. Afterwards, the chars were cooled under a flow of nitrogen to room temperature. The char samples were ground and sieved to a size of $<150 \mu \mathrm{m}$ for the gasification experiments.

\subsection{Gasification tests}

Thermogravimetric analysis is a technique frequently used for the determination of kinetic parameters of carbonaceous materials $(15,16,17)$. A thermobalance (Setaram TAG 24) was used for the gasification tests which were conducted at atmospheric pressure. The sample was 
deposited in a crucible with a circular base ( $5 \mathrm{~mm}$ diameter and $2 \mathrm{~mm}$ height). The amount of sample used was around $6 \mathrm{mg}$. A thermocouple was located close to the platinum basket to monitor temperature and to close the oven control loop. In this work, all the experiments were performed under isothermal conditions at different temperatures depending on the nature of the sample $(998-1323 \mathrm{~K})$. The total flow rate of the reactive gas introduced into the thermobalance during the experiments was $150 \mathrm{~cm}^{3} / \mathrm{min}$. The steam generator consisted of a $\mathrm{CEM}^{\circledR}$ (Controlled Evaporator and Mixer from Bronkhorst High-Tech), in which water and $\mathrm{N}_{2}$ are mixed and heated up to the desired temperature $(423 \mathrm{~K})$. Liquid and mass flow controllers were used to control the flow rates of water and nitrogen in order to ensure that the desired steam concentration remained constant (10-40\% vol.).

\section{Results and discussion}

A general kinetic expression for the overall reaction rate may be written as follows (18):

$$
\frac{d X}{d t}=k\left(C_{g}, T\right) f(X)
$$

where $k$ is the apparent gasification reaction rate, which includes the effect of temperature (T) and the effect of the gasifying agent concentration $\left(\mathrm{C}_{\mathrm{g}}\right)$, and $f(X)$ describes the changes in physical or chemical properties of the sample as the gasification proceeds. Assuming that the concentration of the gasifying agent remains constant during the process, the apparent gasification reaction rate is dependent on the temperature and can be expressed using the Arrhenius equation, which is written as:

$$
k=k_{0} e^{-E_{a} / R T}
$$

where $k_{0}$ and $E_{a}$ are the pre-exponential factor and activation energy, respectively.

In this work, three models were applied in order to describe the reactivity of the chars studied: the Volumetric Model (VM), the Grain Model (GM) and the Random Pore Model (RPM). These models give different formulations of the term $f(X)$. The VM assumes a homogeneous reaction throughout the particle and a linearly decreasing reaction surface area with conversion (19). The overall reaction rate is expressed by:

$$
\frac{d X}{d t}=k_{V M}(1-X)
$$


The Grain Model or shrinking core model, proposed by Szekely and Evans, (20) assumes that a porous particle consists of an assembly of uniform nonporous grains and the reaction takes place on the surface of these grains. The space between the grains constitutes the porous network. The shrinking core behaviour applies to each of these grains during the reaction. In the regime of chemical kinetic control and assuming the grains have a spherical shape, the overall reaction rate is expressed in these models as:

$$
\frac{d X}{d t}=k_{G M}(1-X)^{2 / 3}
$$

This model predicts a monotonically decreasing reaction rate and surface area because the surface area of each grain is receding during the reaction.

The Random Pore Model considers the overlapping of pore surfaces, which reduces the area available for reaction (21). The basic equation for this model is:

$$
\frac{d X}{d t}=k_{R P M}(1-X) \sqrt{ }[1-\psi \ln (1-X)]
$$

This model is able to predict a maximum for the reactivity as the reaction proceeds, as it considers the competing effects of pore growth during the initial stages of gasification, and the destruction of the pores due to the coalescence of neighbouring pores as the reaction proceeds. The RPM model contains two parameters, the reaction rate constant, $k_{R P M}$, and $\psi$, which is a parameter related to the pore structure of the unreacted sampled $(X=0)$ by:

$$
\psi=\frac{4 \pi L_{0}\left(1-\varepsilon_{0}\right)}{S_{0}^{2}}
$$

where $S_{0}, L_{0}$ and $\varepsilon_{0}$ represent the pore surface area, pore length, and solid porosity, respectively. Another approach to estimate $\psi$ is from the experimental conversion values where the reaction rate is maximum, $\mathrm{X}_{\max }$. By differentiation of Eq.5, $\psi$ can be determined in terms of $\mathrm{X}_{\max }$ as:

$$
\psi=\frac{2}{\left(2 \ln \left(1-X_{\max }\right)+1\right)}
$$


In order to evaluate these models using the experimental results, Equations 3-5 were linearised after the separation of variables and integration, giving:

$$
\begin{aligned}
& -\ln (1-X)=k_{V M} t \\
& 3\left[1-(1-X)^{1 / 3}\right]=k_{G M} t \\
& (2 / \psi)\left[(1-\psi \ln (1-X)-1]=k_{R P M} t\right.
\end{aligned}
$$

The reaction rate constants $\left(\mathrm{k}_{\mathrm{VM}}, \mathrm{k}_{\mathrm{GM}}, \mathrm{k}_{\mathrm{RPM}}\right)$ were calculated using the experimental results obtained with $20 \%$ of steam at different temperatures, from the slope of the plots of Equations $8-10$.

Figure 1 shows the application of the three models to the experimental results obtained for the gasification of chars PT and $\mathrm{CH}$ at different temperatures. In this study a range of conversions from 0.1 to 0.9 was used. Then, by using the reaction rate constants calculated at different temperatures, the activation energy $\left(E_{a}\right)$ and the pre-exponential factor $\left(k_{0}\right)$ were obtained from the Arrhenius plot (ln k vs. 1/T).

$$
k=k_{0} e^{E_{a} / R T}
$$

However, this method must be applied using the results obtained under the chemical controlled regime. The change between the chemical and diffusional controlled regime can be detected from the change in the slope on the Arrhenius plot. Figure 2 shows the Arrhenius plots for the chars using the reaction rates calculated with the RPM model. From these plots, the kinetic parameters were derived for the three models used. Table 2 shows the preexponential factor, $k_{0}$, and activation energy, $E_{a}$, obtained by applying of the different models. In the case of the RPM, $\psi$ was used as a fitting parameter. It can be seen that the $E_{a}$ values are similar for the three models, and the main differences relate to the pre-exponential factor.

In order to compare the validity of each model, the experimental conversion was compared with the calculated values at the different temperatures used. The results obtained are shown in Figure 3. A good prediction for the conversion of the PT and PC chars is achieved with the RPM and GM models, while the VM model clearly overpredicts the conversion at all the temperatures studied. In the case of the WI char, the three models make a good prediction of the conversion. A similar result is obtained with the $\mathrm{CH}$ char, except at $1123 \mathrm{~K}$, where the 
GM model underpredicts the conversion. However, during the gasification of the OS chars, the GM and VM models do not predict the experimental conversion data properly, and only the RPM model gives acceptable results.

The reactivity $(\mathrm{dX} / \mathrm{dt})$ of the chars during gasification at the different conditions was calculated using the kinetic parameters and compared with the experimental results. Figure 4 shows the results obtained for the different temperatures. Reactivity of the PT char presents a maximum at low conversions (0.2-0.3). For this char, the RPM model gives the best fit, as this model is able to predict this type of behaviour.

The reactivity of the WI and $\mathrm{CH}$ chars shows a constant decrease with conversion. For these chars, the VM and RPM models give a good prediction, while the results obtained with the GM model are markedly lower than the experimental values. The RPM model presents a low value of $\psi$ for the WI and $\mathrm{CH}$ chars, as can be seen in Table 2. When this parameter approaches zero, this model predicts a constant decrease in reactivity with conversion, as does the VM model. The reactivity of the PC char decreases rapidly at high conversions. For this char, the reactivity values calculated with the GM and RPM models are in agreement with the experimental results. Finally, the reactivity of the OS char shows a maximum at high conversions (0.7-0.8).

The maximum reaction rate predicted using the RPM model, for high values of $\psi$, is restricted to a conversion of 0.39 . The reactivity behaviour exhibited by the OS char, with a maximum at high conversions, is usually attributed to a strong catalytic contribution of indigenous alkali $(22,23)$, and cannot be described properly with the models used in this work as they only take into account structural changes during gasification. The elemental composition of the $\mathrm{CH}$ and OS chars was qualitatively studied by means of EDX. From this analysis, it was observed that both chars have a similar elemental composition, except in the case of potassium. The concentration of this element is much higher in the case of the OS char, which could explain its high reactivity (24).

In order to quantify the errors produced with each model when calculating the values of conversion and reactivity, the average of the errors between the experimental and calculated results at the different experimental conditions was determined. The results obtained are summarised in Table 3. As can be seen, the best conversion calculated values were obtained with the RPM for all the samples, as this model gave rise to the lowest errors. In the case of the OS char, the error obtained using the RPM model is high compared with the other chars, but quantitatively lower than that of the GM and VM models. 
Regarding the variation in the reactivity with conversion, the discrepancies between the experimental and calculated values are higher than those corresponding to the conversion. In general, the RPM model calculates the variation in the reactivity of the chars more accurately than the other models. The greater complexity of this model allows a wider range of behaviours to be predicted than the other models. Only the GM model is able to predict more accurately the reactivity of the PC char, but the differences with RPM model are negligible.

The effect of steam concentration on the gasification reactivity of the chars was studied using the RPM model. For this purpose, different gasification tests were carried out under different steam concentrations (10-40\%) at a fixed temperature for each char. The dependence of reaction rate constant on the reaction order (n) can be described by means of the following equation:

$$
k=k^{\prime} C_{H_{2} O}^{n}
$$

The reaction rate $(\mathrm{k})$ was calculated using the RPM, and from the slope of the log-log plot of the reaction rate vs. the steam concentration, the reaction order with respect to the steam concentration, $n$, was calculated (see Figure 5). The results obtained are presented in Table 4. The values obtained are in agreement with those found by other authors for coals $(11,25)$. The dependence of the biomass char reactivity on the steam concentration is similar to that of the coal chars, as similar reaction order values are obtained.

Finally, the reactivity of the chars under gasification with steam was compared. A parameter that is commonly used to compare the gasification reactivities of different fuels is the reactivity index, $R$, which is defined as:

$$
R=\frac{0.5}{\tau_{0.5}}
$$

where $\tau_{0.5}$ represents the time required to reach $50 \%$ carbon conversion. High reactivity index values are associated with high reactivities. The reactivity indexes calculated during gasification with $20 \%$ of steam at a temperature of $1173 \mathrm{~K}$ are summarized in Table 4 . The reactivity indexes of PT, WI and PC during gasification are $0.98,0.30$ and $0.15 \mathrm{~h}^{-1}$, respectively. Therefore, the higher the volatile matter content, the higher the reactivity, which is in agreement with the results reported by many investigators $(8,26,27)$. For the biomass 
samples, $\mathrm{CH}$ and $\mathrm{OS}$, the $R$ values are 1.85 and $8.09 \mathrm{~h}^{-1}$, respectively. These values reveal the higher reactivity of the biomass compared to that of coal during gasification. However, the reactivity index of the OS char is more than four times higher than that of $\mathrm{CH}$ char, despite the similarities between the proximate and ultimate analyses of these samples. This is a clear evidence of the strong effect that catalysed reactions exert during the gasification of some types of biomass.

\section{Conclusions}

Five different fuel chars were gasified in a thermobalance at atmospheric pressure with steam, with the aim of studying their reactivity at different temperatures and steam concentrations. In this study, the ability of three mathematical models (volumetric, grain and random pore models) to predict the conversion and the reactivity of the chars was assessed. The Random Pore Model was found to be the most suitable model for predicting the behaviour of the chars during steam gasification. This model is able to predict accurately the conversion and reactivity of four samples (PT, WI, PC, $\mathrm{CH}$ ) as gasification proceeds. However, the OS char presented a different behaviour from the other chars during gasification, and its reactivity appeared to be influenced by catalytic effects. For this sample, none of the models were able to predict properly the behaviour of the char.

Kinetic parameters were derived for char gasification using the different models. The activation energy calculated with the models was similar for each sample, the main differences being encountered for the pre-exponential factor. In addition, the effect of steam concentration on char gasification was studied. The reaction orders for each char were calculated, and values from 0.4 to 0.7 were obtained.

The reactivity of the chars was compared using a reactive index that takes into account the time required to reach a conversion of $50 \%$. Char reactivity was found to depend on volatile matter content of the parent coal. The two types of biomass employed presented a high reactivity compared to the other samples. However, considerable differences were also encountered between the two biomass samples used in these experiments. 


\section{References}

1 S. Dunn, International Journal of Hydrogen Energy, 27 (2002) 235.

2 V. Strezov, B. Moghtaderi, J.A. Lucas, J. Therm. Anal. Cal., 72 (2003) 1041.

3 L. Nuñez-Regueira, L. Rodríguez-Añón, J. Proupin-Castiñeiras and A. Romero-García, J. Therm. Anal. Cal., 66 (2001) 281.

4 C. Wolters and M. Kanaar, Proceedings of the $2^{\text {nd }}$ International Conference on Clean Coal Tecnologies for our future. Castiadas (Calgari, Sardinia), 10-12 May (2005).

5 R.C. Everson and H.W.J.P. Neomagus, Fuel, 85 (2006) 1076.

6 L. Douglas, and P.J. Smith, Coal combustion and gasification, Plenum Press, New York, 1985.

7 A. Molina and F. Mondragón, Fuel, 77 (1998) 1831.

8 K. Miura, K. Hashimoto, and P. Silverston, Fuel, 68 (1989) 1461.

9 C.V. Calahorro, T.C. Cano, A.B. García and V.G. Serrano, J. Therm. Anal. Cal., 32 (1987) 1063.

10 C.V. Calahorro, A.B. García, V.G. Serrano, J. Therm. Anal. Cal., 30 (1985) 597.

11 L. Zhang, J. Huang, Y. Fang and Y. Wang, Energy \& Fuels, 20 (2006) 1201.

12 M. Sakawa, Y. Sakurai and Y. Hara, Fuel, 61 (1982) 717.

13 M. Sahimi, G.R. Gavalas and T.T. Tsotsis, Chem. Eng. Sci., 45 (1990) 1443.

14 H. Barkia, L. Belkbir, S.A.A. Jayaweera, J. Therm. Anal. Cal., 76 (2004) 623.

15 I.Y. Elbyli and S. Piskin, J. Therm. Anal. Cal., 83 (2006) 721.

16 H. Barkia, L. Belkbir, S.A.A. Jayaweera, J. Therm. Anal. Cal. 86 (2006) 121.

17. M.V. Kök, A.G. Iscan, J. Therm. Anal. Cal., 88 (2007) 657.

18 G.Q. Lu and D.D. Do, Carbon, 32 (1994) 247. 
19 M. Ishida and C. Y. Wen., Chem. Eng. Sci., 26 (1971) 1031.

20 J. Szekely and J.W. Evans, Chem. Eng. Sci., 26 (1970) 1091.

21 S.K. Bhatia and D.D. Perlmutter, AIChE Journal, 26 (1980) 379.

22 R.P.W.J Struis, C. von Scala, S. Stucki, and R. Prins, Chemical Engineering Science, 57 (2002) 3581.

23 R.P.W.J Struis, C. von Scala, S. Stucki, and R. Prins, Chemical Engineering Science, 57 (2002) 3593.

24 K. Miura, M. Aimi, T. Naito, K. Hashimoto, Fuel, 65 (1985) 407.

25 A. Linares-Solano, O.P. Mahajan and P.L. Walker, Fuel, 58 (1979) 327.

26 D.P. Ye, J.B. Agnew and D.K. Zhang, Fuel, 77 (1998) 1209.

27 T. Takarada, Y. Tamai and A. Tomita, Fuel, 64 (1985) 1438. 


\section{List of tables}

Table 1. Proximate and ultimate analyses of the samples

Table 2. Comparison of the kinetic parameters of the PT, WI, PC and CH chars during steam gasification for the VM, GM and RPM models.

Table 3. Errors produced between the experimental and theoretical conversion (X) and reaction rate $(\mathrm{dX} / \mathrm{dt})$ data

Table 4. Reaction order (n) of the chars with respect to steam, and the reactivity index (R) calculated at a steam concentration of $20 \%$.

\section{List of figures}

Figure 1. Plots of the VM, GM and RPM linearised models for the PT (a, b, c) and CH (d, e, f) chars during steam gasification (20\% vol.) at different temperatures.

Figure 2. Arrhenius plots for the GM model of the PT, WI, PC, CH and OS chars during steam gasification (20\% vol.).

Figure 3. Comparison between the experimental conversion and that predicted by the VM, GM and RPM models vs. time for steam gasification (20\% vol.) of the PT, WI, PC, CH and OS chars at different temperatures.

Figure 4. Comparison between the experimental reaction rate and that predicted by the VM, GM and RPM models vs. conversion for steam gasification (20\% vol.) of the PT, WI, PC, $\mathrm{CH}$ and $\mathrm{OS}$ chars at different temperatures.

Figure 5. Reactivity of the PT, WI, PC and $\mathrm{CH}$ chars as a function of steam concentration. 
Table 1. Proximate and ultimate analyses of the samples

\begin{tabular}{cccccccc}
\hline Sample & \multicolumn{3}{c}{ Proximate Analysis (wt.\%) } & \multicolumn{5}{c}{ Ultimate Analysis (wt.\%, daf) } \\
\cline { 2 - 7 } & Ash (db) & V.M.(daf) & C & H & N & S & O $^{*}$ \\
\hline WI & 7.9 & 18.3 & 91.1 & 5.0 & 1.2 & 0.6 & 2.1 \\
PT & 39.3 & 39.3 & 74.4 & 5.0 & 1.6 & 1.4 & 17.6 \\
PC & 0.4 & 10.7 & 88.0 & 3.7 & 1.6 & 5.7 & 0.80 \\
CH & 1.2 & 81.6 & 50.3 & 5.8 & 0.1 & 0.0 & 43.8 \\
OS & 0.5 & 82.8 & 50.9 & 6.0 & 0.1 & 0.0 & 43.0 \\
\hline
\end{tabular}

dry basis (db), dry ash free basis (daf).

* determined by difference.

Table 2. Comparison of the kinetic parameters of the PT, WI, PC and CH chars during steam gasification for the VM, GM and RPM models

\begin{tabular}{cccccccc}
\hline & \multicolumn{2}{c}{ Volumetric Model $(\mathrm{VM})$} & \multicolumn{2}{c}{ Grain Model $(\mathrm{GM})$} & \multicolumn{3}{c}{ Random Pore Model (RPM) } \\
\hline & $\mathrm{E}_{\mathrm{a}}(\mathrm{kJ} / \mathrm{mol})$ & $\mathrm{k}_{0}\left(\mathrm{~s}^{-1}\right)$ & $\mathrm{E}_{\mathrm{a}}(\mathrm{kJ} / \mathrm{mol})$ & $\mathrm{k}_{0}\left(\mathrm{~s}^{-1}\right)$ & $\mathrm{E}_{\mathrm{a}}(\mathrm{kJ} / \mathrm{mol})$ & $\mathrm{k}_{0}\left(\mathrm{~s}^{-1}\right)$ & $\psi$ \\
\hline PT & 214 & $1.54 \times 10^{6}$ & 215 & $1.24 \times 10^{6}$ & 215 & $1.01 \times 10^{6}$ & 2.5 \\
WI & 189 & $3.34 \times 10^{4}$ & 188 & $2.40 \times 10^{4}$ & 188 & $2.96 \times 10^{4}$ & 0.3 \\
PC & 171 & $2.97 \times 10^{3}$ & 171 & $2.22 \times 10^{3}$ & 171 & $1.83 \times 10^{3}$ & 2.3 \\
$\mathrm{CH}$ & 238 & $2.07 \times 10^{7}$ & 239 & $1.64 \times 10^{7}$ & 238 & $1.93 \times 10^{7}$ & 0.2 \\
$\mathrm{OS}$ & 167 & $8.87 \times 10^{4}$ & 167 & $7.05 \times 10^{4}$ & 167 & $2.21 \times 10^{4}$ & 39.0 \\
\hline
\end{tabular}


Table 3. Errors produced between experimental and theoretical conversion (X) and reaction rate $(\mathrm{dX} / \mathrm{dt})$ data

\begin{tabular}{lccccccc} 
& \multicolumn{3}{c}{ Error X (\%) } & \multicolumn{3}{c}{ Error dX/dt (\%) } \\
\cline { 2 - 4 } & RPM & VM & GM & & RPM & VM & GM \\
\hline PT & 2.52 & 19.06 & 7.22 & & 5.13 & 21.51 & 9.42 \\
WI & 3.88 & 6.14 & 7.41 & & 7.77 & 8.72 & 15.66 \\
PC & 5.30 & 17.34 & 6.43 & & 11.04 & 22.97 & 10.82 \\
CH & 3.35 & 5.20 & 6.63 & & 7.67 & 8.40 & 16.57 \\
OS & 23.32 & 49.68 & 35.91 & & 28.82 & 57.53 & 55.15 \\
\hline
\end{tabular}

Table 4. Reaction order (n) of the chars with respect to steam and the reactivity index with a steam concentration of $20 \%$

\begin{tabular}{cccccccc}
\hline Sample & PT & WI & PC & CH & OS & PSOC-91 & Anthracitic coals $^{(9)}$ \\
\hline $\mathrm{n}$ & 0.63 & 0.72 & 0.70 & 0.40 & 0.52 & 0.58 & $0.46-0.64$ \\
\hline $\mathrm{R}\left(\mathrm{h}^{-1}\right)$ & 0.98 & 0.30 & 0.15 & 1.85 & 8.09 & --- & --- \\
\hline
\end{tabular}



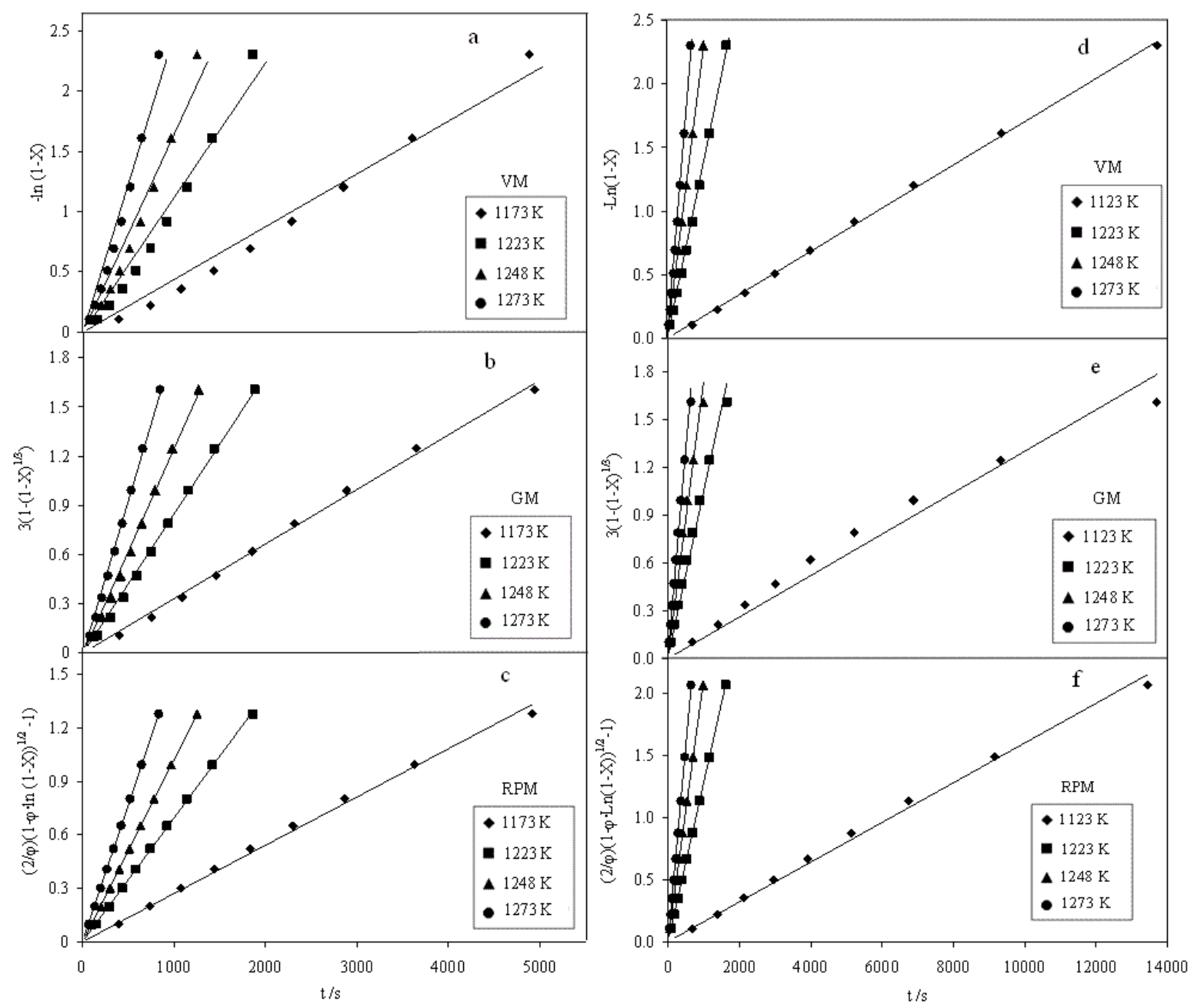

Figure 1. Plots of the VM, GM and RPM linearised models for the PT (a, b, c) and CH (d, e, f) chars during steam gasification (20\% vol.) at different temperatures. 


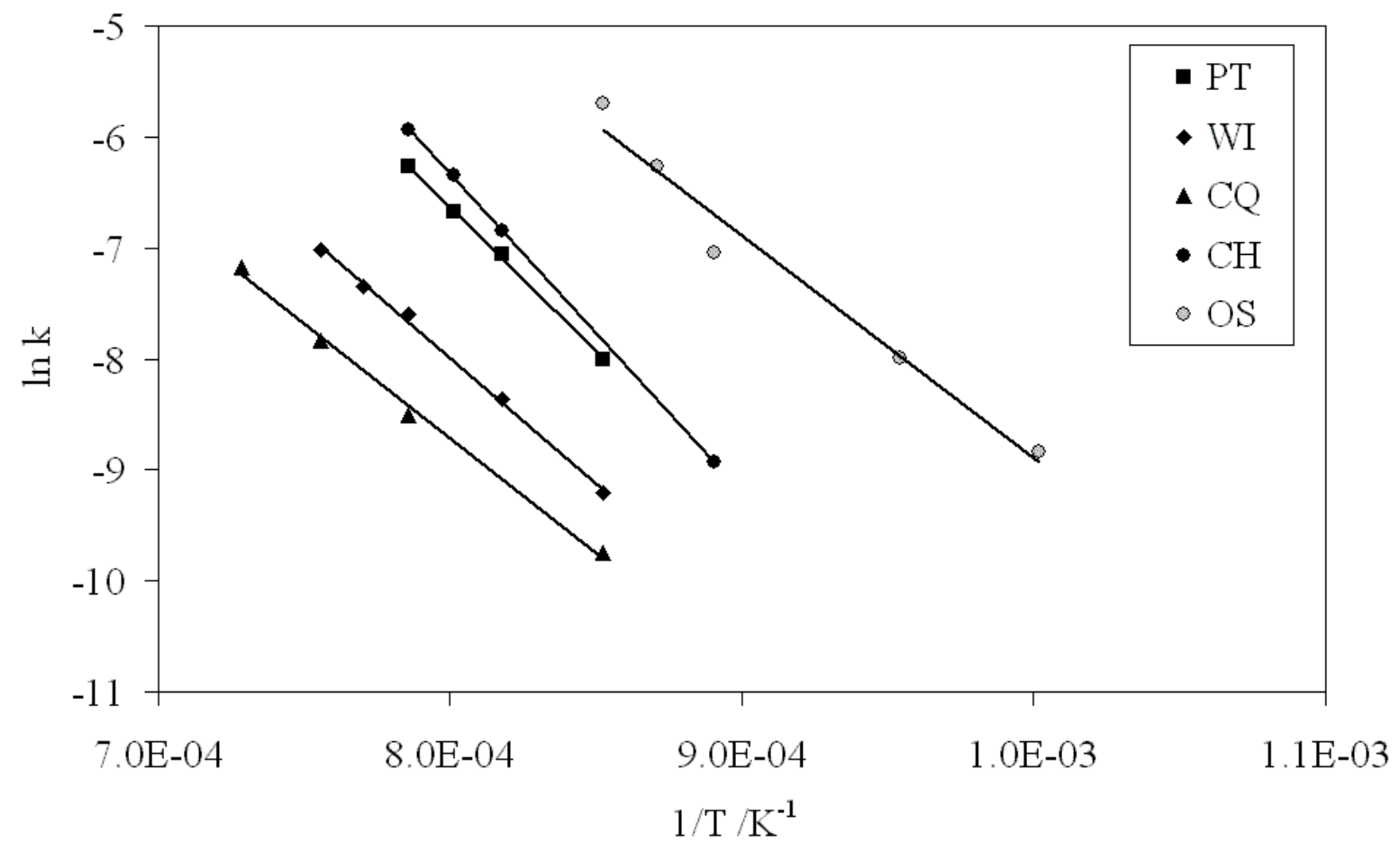

Figure 2. Arrhenius plots for the GM model of the PT, WI, PC, CH and OS chars during steam gasification (20\% vol.). 

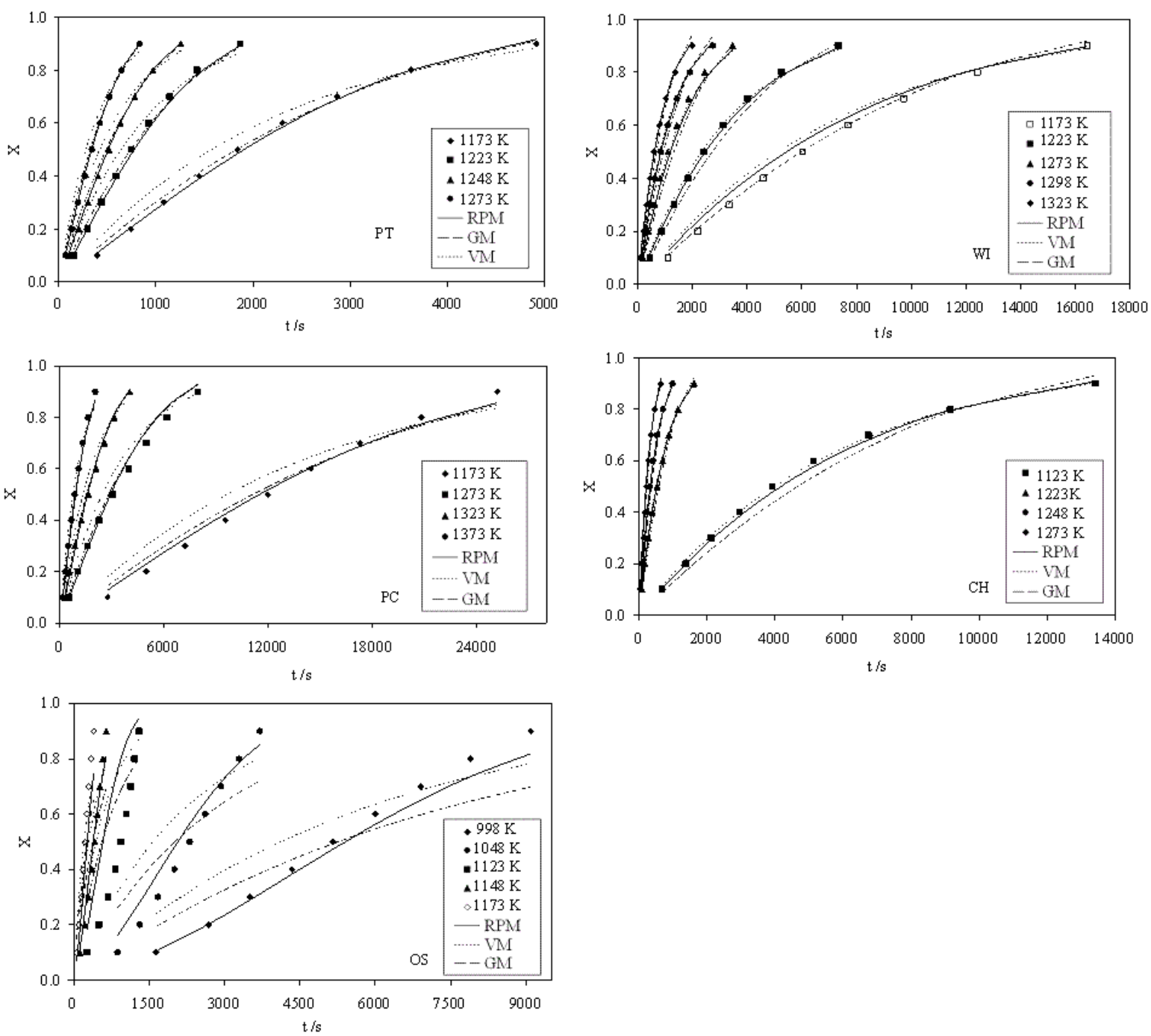

Figure 3. Comparison between the experimental conversion and that predicted by the VM, GM and RPM models vs. time for steam gasification (20\% vol.) of the PT, WI, PC, CH and OS chars at different temperatures. 

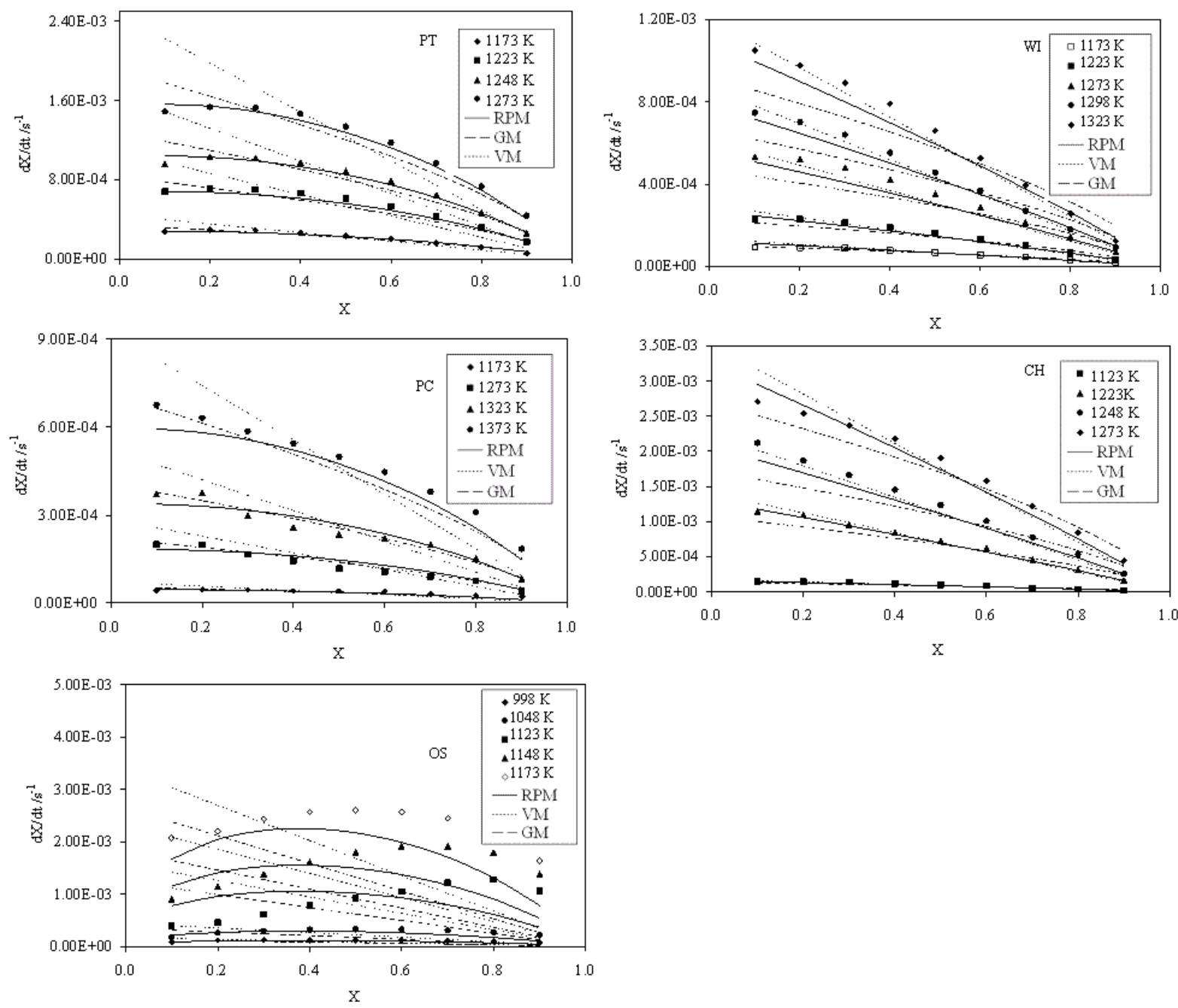

Figure 4. Comparison between the experimental reaction rate and that predicted by the VM, GM and RPM models vs. conversion for steam gasification (20\% vol.) of the PT, WI, PC, $\mathrm{CH}$ and OS chars at different temperatures. 


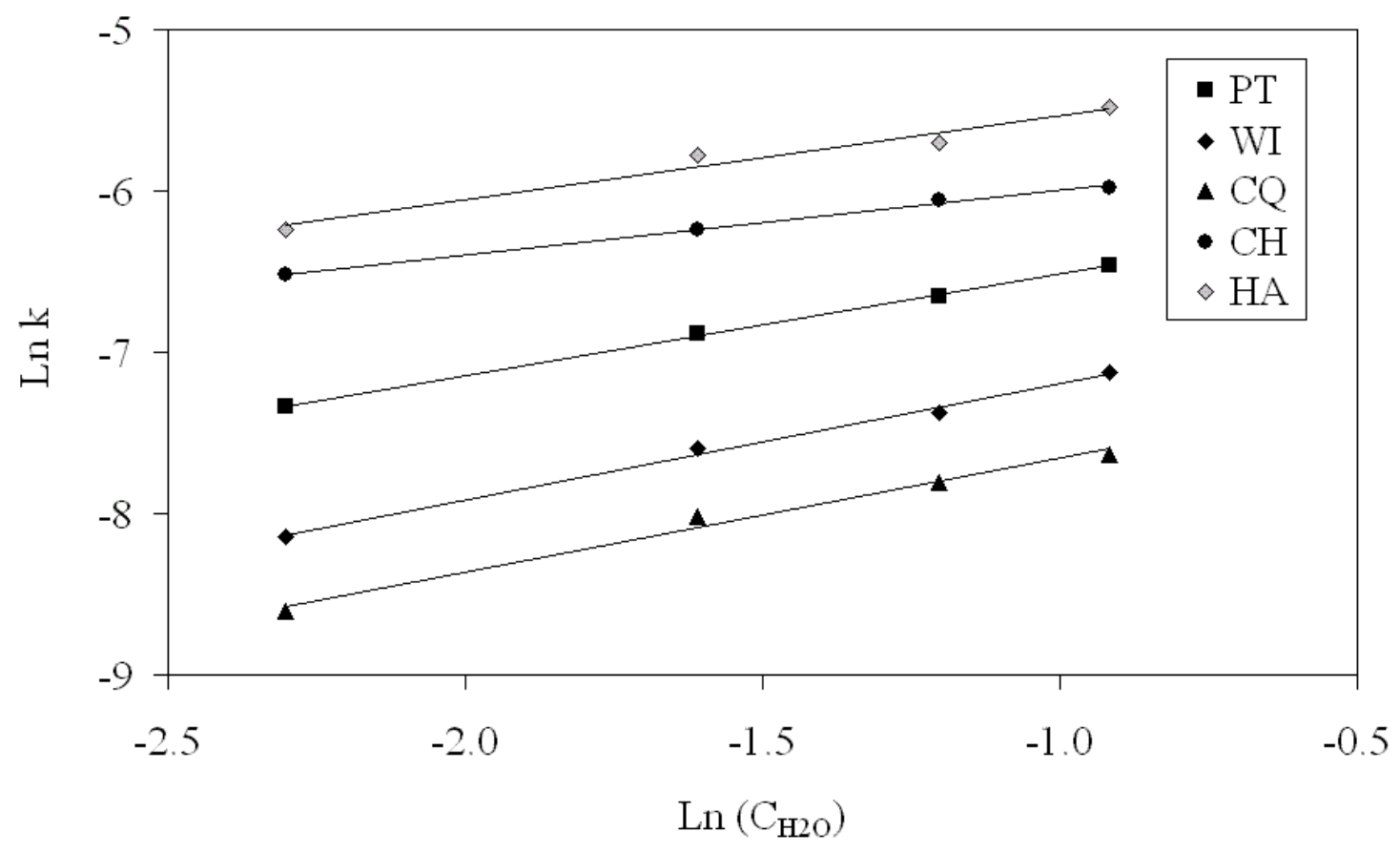

Figure 5. Reactivity of the PT, WI, PC and $\mathrm{CH}$ chars as a function of steam concentration. 